\title{
Preparation of Flax Residue Activated Carbon by KOH Method and Its Electrode Performance
}

\author{
Bing Wang, Shujun Li, Wenying Tan \\ School of Material Science and Engineering, Northeast Forestry University, Key Laboratory of Biomass Material Science and \\ Technology of Ministry of Education of China, Harbin, China \\ Email: 1908412957@qq.com
}

How to cite this paper: Wang, B., Li, S.J. and Tan, W.Y. (2021) Preparation of Flax Residue Activated Carbon by $\mathrm{KOH}$ Method and Its Electrode Performance. Materials Sciences and Applications, 12, 417-435. https://doi.org/10.4236/msa.2021.129028

\section{Received: July 25, 2021}

Accepted: September 23, 2021

Published: September 26, 2021

Copyright ( 2021 by author(s) and Scientific Research Publishing Inc. This work is licensed under the Creative Commons Attribution International License (CC BY 4.0).

http://creativecommons.org/licenses/by/4.0/

(c) (i) Open Access

\begin{abstract}
In this study, activated carbon was prepared by the potassium hydroxide activation method with flax residues as raw materials. High-quality activated carbon was prepared by single factor and orthogonal experiments. Iodine adsorption and methylene blue adsorption were used as performance indicators. As prepared activated carbon was characterized by XRD, XPS and SEM. The results showed that the optimized electrode material was prepared under an impregnation ratio of $1: 2$, activation temperature of $800^{\circ} \mathrm{C}$ and activation time of $100 \mathrm{~min}$. The yield of activated carbon was $49.48 \%$, the iodine value was $1667.13 \mathrm{mg} / \mathrm{g}$ and the methylene blue value was $429 \mathrm{mg} / \mathrm{g}$. The specific surface area measured by the automatic porosity analyzer is $1221 \mathrm{~m}^{2} / \mathrm{g}$, and the mass-specific capacitance is $215.7 \mathrm{~F} / \mathrm{g}$ under current density of $0.1 \mathrm{~A} / \mathrm{g}$.
\end{abstract}

\section{Keywords}

Flax Residue, Activated Carbon, Activation, Electrochemical Performance, Electrode Material

\section{Introduction}

In recent years, with the rapid growth of the world population and rapid economic development, people's living standards have been constantly improved, and science and technology have also been continuously improved [1]. People have begun to invest more in the development of energy-saving and green new energy technologies, so the development of new energy and new energy storage device have become one of the hot issues studied by global researchers. Conventional capacitors had very low capacity and cannot meet the power density requirements [2], therefore, the supercapacitor was born. The supercapacitor, also known as the electrochemical capacitor, was developed in the 1980s as a new 
type of energy storage device between conventional capacitors and batteries [3]. As electrode material is the core component of the supercapacitor, the development of electrode material with excellent supercapacitor performance has become the focus of research [4]. In recent years, various new materials have emerged to improve the performance of capacitors, among which porous carbon materials are widely used in supercapacitors because of their good stability and charging/discharging performance. Among them, activated carbon has a simple fabrication process, low cost, well-developed pores, and large specific surface area [5], as well as high electrochemical stability and good electrical conductivity. It has long been used as the first choice for the preparation of supercapacitor electrodes.

At present, many supercapacitor electrode materials have been developed using carbon-containing precursors, but the results of the current study still cannot meet the demand for higher performance. The development of cheap and advanced carbon electrode materials by $\mathrm{KOH}$ activation is a key direction in the field of supercapacitors [6]. The relationship between the microstructure of porous carbon prepared by the $\mathrm{KOH}$ method and the corresponding capacitive properties is not clear. Indeed, porous carbon prepared by the $\mathrm{KOH}$ method is typically amorphous, therefore, it is of great significance to select a suitable carbon source and prepare alternative porous carbon materials with the $\mathrm{KOH}$ method.

Preliminary studies on electrode performance prepared from corn straw [7] [8], coconut husk [9], rice husks [10], pepper stalks [11], and microorganisms [12] [13] have been carried out in China and abroad. However, there are few studies on electrode performance related to flax residue-activated carbon. The activated carbon prepared by flax residue has abundant pores and a large specific surface area, and it is due to the fact that flax residue contains more lignin and hemicellulose [14]. Flax residue has the advantage of being simple and easy to obtain, therefore, flax residue was selected as raw material for the preparation of activated carbon electrodes, as well as the feasibility of flax residue for electrode preparation was investigated and its electrode performance was further investigated in detail.

\section{Experimental}

\subsection{Raw Materials}

The flax residues used in this study were obtained from Zhaoyuan, China. The flax residue was purged, crushed with a pulverizer and screened out $18-20$ mesh.

\subsection{Reagents and Instrument}

The chemical reagents and drugs used in the experiment and their manufacturers are shown in Table 1.

The main equipment used in the experiment and its manufacturers are shown in Table 2. 
Table 1. Experimental reagents.

\begin{tabular}{ccc}
\hline & \multicolumn{2}{c}{ Experimental Reagents } \\
\hline Reagent & Grade & Manufacturers \\
\hline Potassium Hydroxide & Analytical Pure & Tianjin Comio Chemical Reagents Co., Ltd \\
Hydroic Acid & Analytical Pure & Tianjin Yongda Chemical Reagents Co., Ltd \\
Diodium Hydrogen Phosphate & Analytical Pure & Tianjin Comio Chemical Reagents Co., Ltd \\
Potassium Dihydrogen Phosphate & Analytical Pure & Tianjin Base Chemical Reagents Co., Ltd \\
Copper Sulfate & Analytical Pure & Tianjin Guangfu Fine Chemical Industry Research Institute \\
Iodine & Analytical Pure & Tianjin Base Chemical Reagents Co., Ltd \\
Potassium Iodide & Analytical Pure & Tianjin Comio Chemical Reagents Co., Ltd \\
Sodium Thiosulfate & Analytical Pure & Tianjin Hengxing Chemical Manufacturing Co., Ltd \\
Soluble Starch & Analytical Pure & Tianjin Yongda Chemical Reagents Co., Ltd \\
Methyl Blue & Analytical Pure & Tianjin Guangfu Fine Chemical Industry Research Institute \\
Sodium Carbonate & Analytical Pure & Tianjin Beichen Founder Reagent Factory \\
Acetonge & Analytical Pure & Tianjin Bohua Chemical Reagents Co., Ltd \\
Ethanol & Analytical Pure & Tianjin Hengxing Chemical Manufacturing Co., Ltd \\
Acetylene Black & Analytical Pure & Fujian Temigao Co., Ltd \\
Adhesive PVC (PTFE) & Analytical Pure & Shanghai Maclin Biochemical Technology Co., Ltd \\
\hline
\end{tabular}

Table 2. Main equipment.

\begin{tabular}{|c|c|c|}
\hline \multicolumn{3}{|c|}{ Main Equipment } \\
\hline Equipment & Model Number & Manufacturers \\
\hline Electronic Balance & ESJ205-4 & Shenyang longteng Electronics Co., Ltd \\
\hline Electric Heat Drum Air Drying Box & DHG-9140A & Shanghai Yiheng Technology Co., Ltd \\
\hline UV Spectrophotomeometer & T6 New Prominent & Beijing Puji General Instrument Co., Ltd \\
\hline Speed Multioscillator & HY-2 & Guohua Electric Appliance Co., Ltd \\
\hline Muffle Furnace & SX2-4-10 & $\begin{array}{l}\text { Tianjin zhonghuan Experimental Electric Furnace Co., } \\
\text { Ltd }\end{array}$ \\
\hline Pipe-Type Furnace & SLG1100-60 & Shanghai Yuntong Test Instrument Co., Ltd \\
\hline Electronic Scanning Microscopy & Quanta 200 & Dutch FEI Company \\
\hline X-Ray Diffractor & D/MAX2200 & Japan Science Co., Ltd \\
\hline $\begin{array}{l}\text { Fully Automatic Specific Surface } \\
\text { Area and Pore Analyzer }\end{array}$ & A SAP2020 & Micromertics, USA \\
\hline Thermal Weight Analyzer & Q 50 & American TA Company \\
\hline Electrochemical Workstation & CHI660E & Shanghai Chenghua Instrument Co., Ltd \\
\hline $\mathrm{X}$-Ray Electron Spectrometer & T HERMO & American Thermal Electron Corporation \\
\hline Vacuum Drying Box & DZF-6020 & Shanghai Yiheng Scientific Instrument Co., Ltd \\
\hline Equipment & Model Number & Manufacturers \\
\hline Electronic Balance & ESJ205-4 & Shenyang Longteng Electronics Co., Ltd \\
\hline
\end{tabular}




\subsection{Preparation of Activated Carbon}

Flax residue was washed and dried in an oven at $105^{\circ} \mathrm{C}-110^{\circ} \mathrm{C}$ to a constant weight. A certain amount of flax residue was weighed into a constant weight crucible, covered and placed in a muffle furnace, and pre-carbonized at $450^{\circ} \mathrm{C}$ for $90 \mathrm{~min}$ to obtain flax residue carbon. According to different impregnation ratios (in this paper, impregnation ratio was the mass ratio of absolutely dry flax residue carbon to $\mathrm{KOH}$ ), $\mathrm{KOH}$ was dissolved in a quantitative amount of water and mixed with the weighed flax residue carbon, and the flax residue carbon/KOH mixture was obtained by impregnation for $6 \mathrm{~h}$ after thorough ultrasonic mixing. After impregnation, it was placed in an oven, dried at $120^{\circ} \mathrm{C}$ to a constant weight, and then placed in a tube furnace with $\mathrm{N}_{2}$ as the protective gas. It was heated up to the activation temperature at a rate of $10^{\circ} \mathrm{C} / \mathrm{min}$, and activated carbon was obtained after a certain period of time. After cooling, the activated carbon was rinsed repeatedly with distilled water until the filtrate was neutral, and then placed in an oven and dried at $120^{\circ} \mathrm{C}$ for $2 \mathrm{~h}$ to obtain activated carbon samples.

\subsection{Orthogonal Test of Activated Carbon}

Factors affecting performances of activated carbon prepared by chemical activation method include activator concentration, activation time, impregnation ratio, activation temperature, impregnation time and impregnation temperature. According to the characteristics of activated carbon prepared by $\mathrm{KOH}$, impregnation ratio (A), activation temperature (B) and activation time $(\mathrm{C})$ were determined. The orthogonal test [15] was performed, the optimized working conditions were determined. The iodine adsorption and methylene blue adsorption of activated carbon was analyzed by range analysis method.

\subsection{Performances of Activated Carbon}

Iodine adsorption and methylene blue adsorption of activated carbon samples were measured according to GB/T13803.1-1999 and GB/T13803.2-1999, respectively. SEM (Quanta 200, the morphological characteristics of flax residue and activated samples were observed at a certain magnification), XRD (X'Pert ${ }^{3}$ Powder X-ray powder diffractometer), XPS (THERMO Photoelectron spectroscopy), BET $\mathrm{N}_{2}$ Adsorption (ASAP 2020 Automatic specific surface area and porosity analyzer by micromertitcs, specific surface area and pore structure of activated carbon were analyzed).

\subsection{Preparation of Working Electrode}

The as-prepared activated carbon was ground homogeneously and the carbon material, acetylene black and PTFE suspension were weighed according to the mass ratio of 8:1:1. The carbon material, PTFE suspension (60\%) and acetylene black were dispersed in anhydrous ethanol and sonicated for half an hour. It was dispersed well, and then it was mixed thoroughly and steamed until it became 
viscous. Then it was applied evenly on nickel foam, dried in a vacuum drying oven at $55^{\circ} \mathrm{C}$ for $12 \mathrm{~h}$. The mass of active substance on the obtained nickel foam was 3 - $5 \mathrm{mg}$; the coating area was about $1.0 \mathrm{~cm}^{2}$. The electrode was then immersed in $6 \mathrm{~mol} / \mathrm{L} \mathrm{KOH}$ solution for $12 \mathrm{~h}$ to ensure that the working electrode was completely wetted for electrochemical testing at room temperature.

\subsection{Measurement of Electrode Performance}

\subsubsection{Cyclic Voltammetry (CV) Testing}

The electrode potential was controlled to change from potential $\varphi_{a}$ to potential $\varphi_{b}$ at a constant rate, and then from $\varphi_{b}$ to $\varphi_{a}$, at the same rate, and changed back and forth between the two potentials; the corresponding response current was recorded. The CV technique could be used to detect the electrode variation process of an unknown electrode system over a wide range of potentials in a short time. The obtained CV curves were analyzed to obtain information such as peak current $\left(I_{p}\right)$, peak potential $\left(\varphi_{p}\right)$, and reaction kinetics. For a given potential scanning rate, response current could be obtained by:

$$
I=C \frac{\mathrm{d} \varphi}{\mathrm{d} t}=C v
$$

where $I$ is the response current, A; $\varphi$ is the potential, $\mathrm{V} ; C$ is the capacitance, $\mathrm{F} ; v$ is the potential scanning rate.

The specific capacitance of electrode material could be calculated by:

$$
C_{g}=\frac{1}{m v\left(V_{2}-V_{1}\right)} \int_{V_{1}}^{V_{2}} I \mathrm{~d} V
$$

where $C_{g}$ is the specific capacitance, $\mathrm{F} / \mathrm{g} ; m$ is electrode mass, $g$; $v$ is the scanning rate, $\mathrm{Vs}^{-1} ; I$ is the current for test, A; $V_{1}$ and $V_{2}$ are low voltage value and high voltage value of the voltage window.

\subsubsection{Charging/Discharging Test}

Charge/discharge test of the study system was conducted with constant current. Constant current charging/discharging curves were used to analyze the process of electrochemical reactions and to calculate the capacity, rate characteristics and cycle life of electrode materials. The specific capacitance could be calculated by:

$$
C_{m}=\frac{i t_{d}}{m \Delta V}
$$

where $C_{m}$ is the specific capacitance per mass, $\mathrm{F} / \mathrm{g} ; i$ is the current, $\mathrm{A}$; $t_{d}$ is the charging time, $s ; \Delta V$ is the voltage window, $\mathrm{V} ; m$ is the mass of activated substances, $g$.

\subsubsection{Characterization by Electrochemical Impedance Spectroscopy (EIS)}

The left side of the Nyquist curve of electrochemical impedance spectra was the high frequency region, where there was a semicircle for non-ideal capacitors, representing the difficulty of electrolyte ions into material. On the right was the 
low frequency region, which was Warburg impedance with a $45^{\circ}$ line. The test frequency range was $10^{-2}-10^{5} \mathrm{~Hz}$, potential amplitude was $5 \mathrm{mV}$.

\section{Results and Analysis}

\subsection{Orthogonal Test of Activated Carbon}

Nine activated carbon samples were prepared according to the three-factor threelevel orthogonal test and the activated carbon preparation process described above. The experimental data were analyzed by range analysis method. The results of iodine adsorption were: $\mathrm{In}$ factor $\mathrm{A}, \mathrm{K}_{1}$ was $3274.93 \mathrm{mg} / \mathrm{g}, \mathrm{K}_{2}$ was $5471.89 \mathrm{mg} / \mathrm{g}$, $\mathrm{K}_{3}$ was $5188.47 \mathrm{mg} / \mathrm{g}$, $\mathrm{R}$ was 732.32 ; In factor $\mathrm{B}, \mathrm{K}_{1}$ was $3991.54 \mathrm{mg} / \mathrm{g}, \mathrm{K}_{2}$ was $4740.81 \mathrm{mg} / \mathrm{g}, \mathrm{K}_{3}$ was $5202.94 \mathrm{mg} / \mathrm{g}$, $\mathrm{R}$ was 403.8 ; In factor $\mathrm{C}, \mathrm{K}_{1}$ was 4744.04 $\mathrm{mg} / \mathrm{g}, \mathrm{K}_{2}$ was $4777.35 \mathrm{mg} / \mathrm{g}, \mathrm{K}_{3}$ was $4413.9 \mathrm{mg} / \mathrm{g}$, $\mathrm{R}$ was 121.15 . Methylene blue adsorption results were: $I n$ factor $A, K_{1}$ was $423 \mathrm{mg} / \mathrm{g}, \mathrm{K}_{2}$ was $990 \mathrm{mg} / \mathrm{g}, \mathrm{K}_{3}$ was $944.5 \mathrm{mg} / \mathrm{g}$, R was 189; In factor B, $\mathrm{K}_{1}$ was $588 \mathrm{mg} / \mathrm{g}, \mathrm{K}_{2}$ was $829.5 \mathrm{mg} / \mathrm{g}, \mathrm{K}_{3}$ was $940 \mathrm{mg} / \mathrm{g}$, R was 117.3; In factor $\mathrm{C}, \mathrm{K}_{1}$ was $817.5 \mathrm{mg} / \mathrm{g}$, $\mathrm{K}_{2}$ was $820 \mathrm{mg} / \mathrm{g}, \mathrm{K}_{3}$ was $720 \mathrm{mg} / \mathrm{g}$, R was 33.33 .

The orthogonal test results of the three factors were compared and analyzed with the R-values, it can be obtained that the optimal levels of iodine adsorption and methylene blue adsorption were $\mathrm{A}_{2} \mathrm{~B}_{3} \mathrm{C}_{2}$, with the order of $\mathrm{A}$ (impregnation ratio) $>\mathrm{B}$ (activation temperature) $>\mathrm{C}$ (activation time), and the best combination was $\mathrm{A}_{2} \mathrm{~B}_{3} \mathrm{C}_{2}$. Considering the adsorption performance of activated carbon, the optimized working conditions under the present experimental conditions could be determined as: impregnation ratio $=1: 2$, activation temperature $=800^{\circ} \mathrm{C}$, activation time $=100 \mathrm{~min}$, optimized activated carbon in the following was activated carbon prepared under optimized working conditions.

\subsection{Parallel Experiments Units}

For the activated carbon prepared under optimized working conditions, three parallel experiments were involved; average yield, average iodine adsorption and average methylene blue adsorption of activated carbon were measured to be $49.5 \%, 1667.1 \mathrm{mg} / \mathrm{g}$ and $429 \mathrm{mg} / \mathrm{g}$, respectively. Its iodine adsorption and methylene blue adsorption were higher than national first-class product standards (iodine adsorption $=1000 \mathrm{mg} / \mathrm{g}$ and methylene blue adsorption $=135 \mathrm{mg} / \mathrm{g}$ according to GB/T13803.2-1999). The best quality activated carbon was initially selected for the electrochemical performance measurement.

\subsection{Characterization of Activated Carbon}

\subsubsection{Characterization by SEM}

Flax residue carbon and activated carbon prepared by $\mathrm{KOH}$ method (activation condition: impregnation ratio $=1: 1,1: 2,1: 3$, activation temperature $=800^{\circ} \mathrm{C}$, activation time $=100 \mathrm{~min})$ were characterized by SEM $(500 \times, 1000 \times, 5000 \times)$. The results were shown in Figure 1.

As shown in Figure 1(a), the surface of flax residue carbon was relatively 


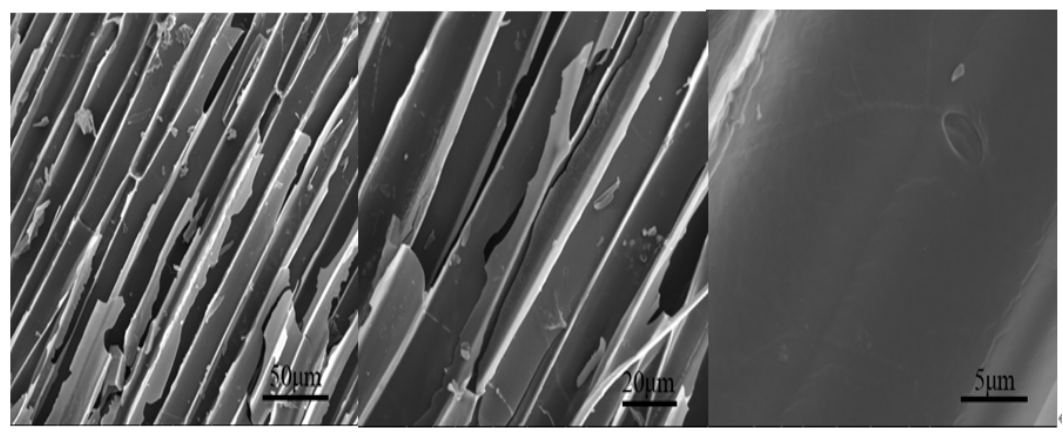

(a)

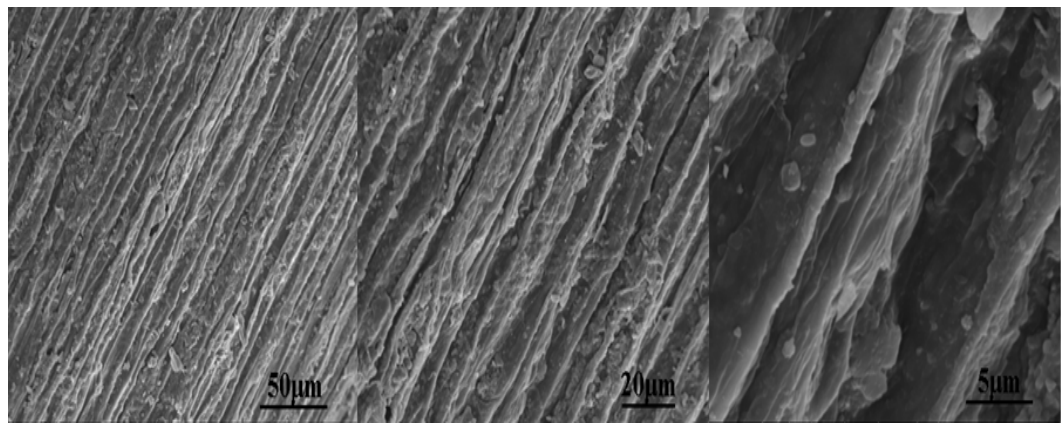

(b)

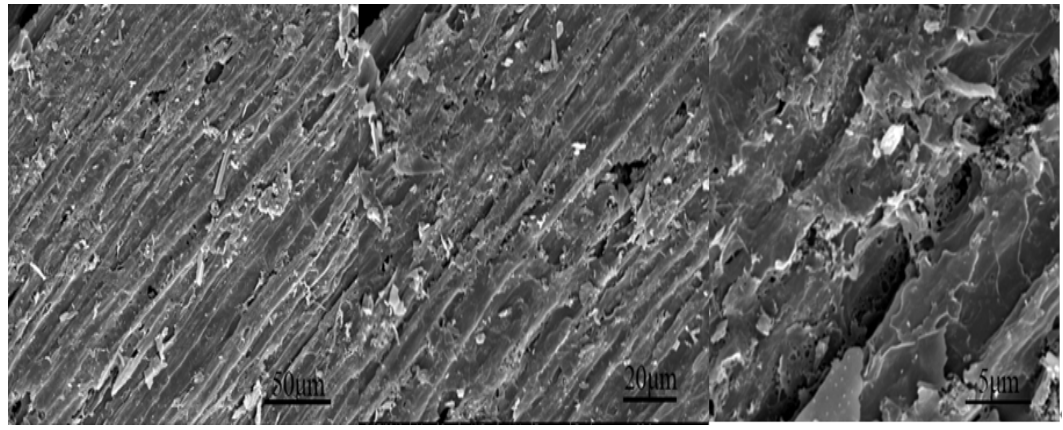

(c)

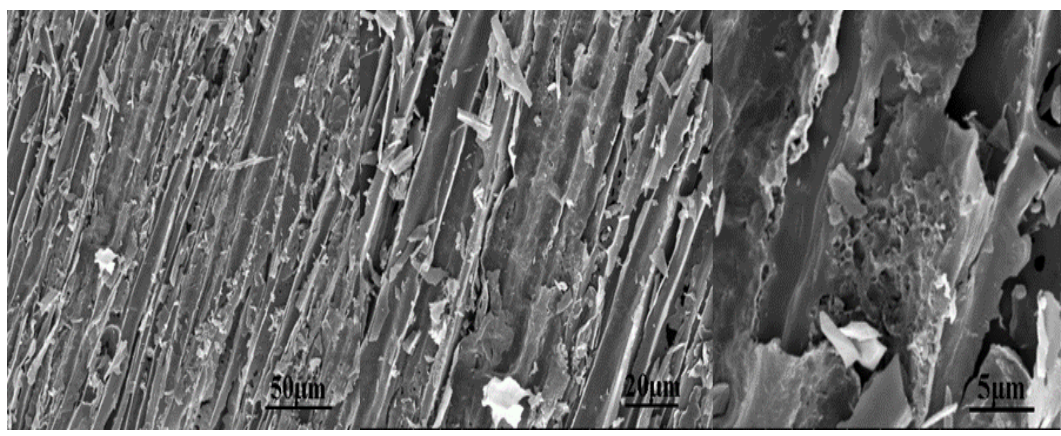

(d)

Figure 1. SEM images of flax residue carbon and activated carbon prepared under different activation conditions. (a) SEM images of flax residue carbon; (b) SEM images of activated carbon (activation condition: impregnation ratio $=1: 1$, activation temperature $=$ $800^{\circ} \mathrm{C}$, activation time $=100 \mathrm{~min}$ ); (c) SEM images of activated carbon (activation condition: impregnation ratio $=1: 2$, activation temperature $=800^{\circ} \mathrm{C}$, activation time $=100$ min); (d) SEM images of activated carbon (activation condition: impregnation ratio $=1: 3$, activation temperature $=800^{\circ} \mathrm{C}$, activation time $=100 \mathrm{~min}$ ). 
smooth and had obvious pores. As shown in Figure 1(b), the impregnation ratio was lower when flax residue carbon was less corrosive. As shown in Figure 1(c) and Figure 1(d), the activated carbon obtained had a rich pore structure, which was conducive to rapid ion transfer/diffusion and accumulation of charges, thus enhancing the electrochemical performance of the material.

Based on possible chemical processes for the preparation of porous carbon materials from the activation of $\mathrm{KOH}$ flax residue carbon [15] [16], it could be concluded that: 1) Redox reactions between carbon and different compounds afforded multi-pore structures; 2) Potassium could enter the carbon pores and led to the expansion of carbon layer [6].

\subsubsection{Characterization by BET}

Specific surface area and pore structure of activated carbon were analyzed by 77 $\mathrm{K}$-temperature static nitrogen adsorption apparatus. The results were shown in Figure 2.
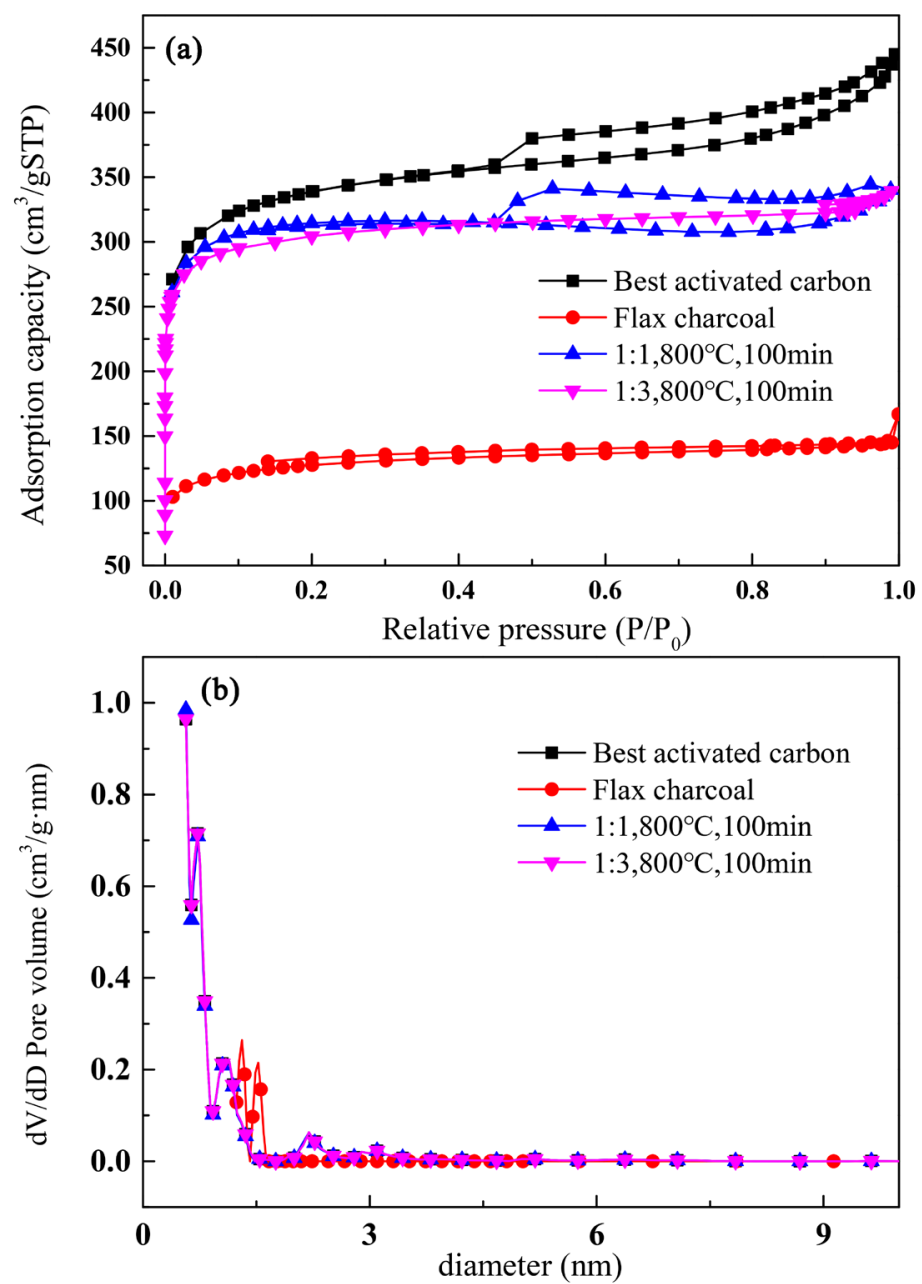

Figure 2. Adsorption/desorption isotherms and pore capacity-pore diameter differential distribution curves of activated carbon prepared under different activation conditions. (a) Adsorption/desorption isotherms of activated carbon (b) pore capacity-pore diameter differential distribution curves of activated carbon. 
As shown in Figure 2(a), according to the International Union of Pure and Applied Chemistry (IUPAC) classification, $\mathrm{N}_{2}$ adsorption/desorption isotherm can be classified as a type IV isotherm. The dramatic increase in the adsorption capacity in low-pressure region indicated a strong interaction between the adsorbent and the adsorbate, which proved the presence of a large number of micropores. In the medium-pressure region, the $\mathrm{N}_{2}$ adsorption/desorption isotherm showed a hysteresis loop, which was caused by capillary coalescence and indicated the presence of mesopore structure in the sample. In the high-pressure region, the $\mathrm{N}_{2}$ adsorption/desorption isotherm bended toward $\mathrm{P} / \mathrm{P}_{0}$ and the curve was horizontal, and the adsorption was close to the limit. Figure 2(b) showed the Non-Local Density Functional Theory (NLDFT) pore size distribution curves; the micropore pore sizes were mainly in the range of 1-2 $\mathrm{nm}$. The abundant void structure was conducive to the rapid transfer/diffusion of ions and the accumulation of charges, which in turn helped to enhance the electrochemical performance of the material. The specific surface area and overall pore capacity of the optimized activated carbon were $1221 \mathrm{~m}^{2} / \mathrm{g}$ and $0.498 \mathrm{~cm}^{3} / \mathrm{g}$, respectively.

\subsubsection{Characterization by XRD}

The XRD patterns of activated carbon and flax residue carbon under different activation conditions are shown in Figure 3. The crystalline structure of the samples was analyzed by XRD (before). The broadened diffraction maxima near $2 \theta=23.38^{\circ}$ and the diffraction maxima at $43.22^{\circ}$ were attributed to graphite- $2 \mathrm{H}$ phase carbon, (002) and (100) Faces, respectively [17]. The low intensity and broad diffraction maxima of XRD indicated low graphitization and high disorder of activated carbon.

Compared with flax residue carbon, the diffraction maxima of Faces (002) and (100) of the optimized activated carbon were broadened and weakened, while

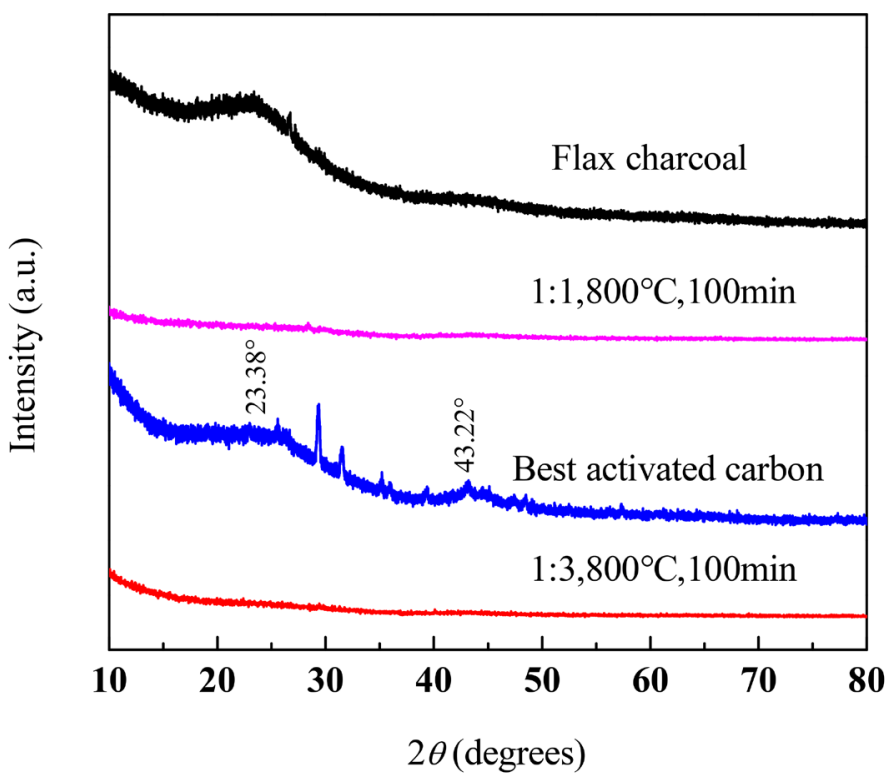

Figure 3. XRD patterns of activated carbon and flax residue carbon under different activation conditions. 
there were no other diffraction maxima. No obvious diffraction maxima were detected in the other two activated carbons, indicating that the activated carbon obtained by $\mathrm{KOH}$ activation was amorphous carbon [18], but all activated samples had a weak diffraction maximum at $43.22^{\circ}$, indicating that the activated samples were mainly disordered [19].

\subsubsection{Characterization by XPS}

XPS was used to determine the elemental composition and chemical state of the prepared materials. Figure 4(c) showed the full XPS spectra of flax residue carbon and activated carbon. As observed, both flax residue carbon and activated carbon contained $\mathrm{C}$ and $\mathrm{O}$ elements. As shown in Figure 4(a), peaks at $284.6 \mathrm{eV}$ corresponded to $\mathrm{C}-\mathrm{C} / \mathrm{C}=\mathrm{C}$, peaks at $286.4 \mathrm{eV}$ corresponded to $\mathrm{C}-\mathrm{O}$, peaks at $288.9 \mathrm{eV}$ corresponded to $\mathrm{C}=\mathrm{O}$, with a decreasing $\mathrm{C}-\mathrm{O}$ content. As shown in Figure 4(b), peaks at $530.5 \mathrm{eV}$ corresponded to $\mathrm{C}=\mathrm{O}$, peaks at $532.2 \mathrm{eV}$ corresponded to $\mathrm{C}=\mathrm{O}$, peaks at $533.5 \mathrm{eV}$ corresponded to $\mathrm{C}-\mathrm{O}-\mathrm{C}$, peaks at $534.6 \mathrm{eV}$ corresponded to $\mathrm{C}-\mathrm{OH}$. Oxygen-containing functional groups were commonly observed on surfaces of porous carbon materials. These groups were usually derived from oxygen remaining on the sample after pyrolysis of precursor, oxygen introduced into the sample by the strong oxidant $\mathrm{KOH}$ activator, and oxygen absorbed from the air [20]. The O1s of all activated carbon samples had three peaks at $530.5,532.2$ and $533.5 \mathrm{eV}$, representing ketone or quinonoid $\mathrm{C}=\mathrm{O}$ carbonyl oxygen, phenolic oxygen and carbonyl oxygen in anhydrides and esters, chemisorbed oxygen and oxygen in water, respectively [21]. In aqueous electrolytes, the pseudocapacitance of porous carbon materials mainly came from the reversible cycle reaction of $\mathrm{O}$ in $\mathrm{C}=\mathrm{O}$, so $\mathrm{O}$ in $\mathrm{C}=\mathrm{O}$ was the main contributor to pseudocapacitance [22]. The abundant oxygen-containing functional groups on the surface increased the active sites on the surface of activated carbon, which could accumulate a large number of electrolyte ions to improve the electrochemical performance of activated carbon [23] [24]. Therefore, although optimized activated carbon had a low degree of graphitization, it still had high electrical conductivity.

\subsection{Capacitance of Activated Carbon}

\subsubsection{Test of Activated Carbon}

Flax residue carbon and activated carbon prepared under different activation conditions were selected for comparison. Activated carbon prepared under different activation conditions were represented with letters, a: flax residue carbon; b: $1: 1$ (impregnation ratio), $800^{\circ} \mathrm{C}, 100 \mathrm{~min}$; $\mathrm{c:} 1: 3$ (impregnation ratio), $800^{\circ} \mathrm{C}$, $100 \mathrm{~min}$;: activated carbon prepared under optimized conditions: 1:2 (impregnation ratio), $800^{\circ} \mathrm{C}, 100 \mathrm{~min}$. Activated carbon was denoted by the above letters in the following content. Electrode performance was investigated using $6 \mathrm{~mol} / \mathrm{L}$ $\mathrm{KOH}$ electrolyte and three-electrode system with 3-5 mg of active substance; the electrodes size was $1 \times 2 \mathrm{~cm}^{2}$, the active material application area was $1 \times 1 \mathrm{~cm}^{2}$, reference electrode was $\mathrm{Hg} / \mathrm{HgO}$ electrode, the counter electrode was a platinum 
electrode of $1 \times 1 \mathrm{~cm}^{2}$, the voltage window was set to $-1-0 \mathrm{~V}$, and the scanning range was $10-200 \mathrm{mV} / \mathrm{s}$. The results were shown in Figure 5(a) (scanning rate was $50 \mathrm{mV} / \mathrm{s}$ ) and Figure 5(b).
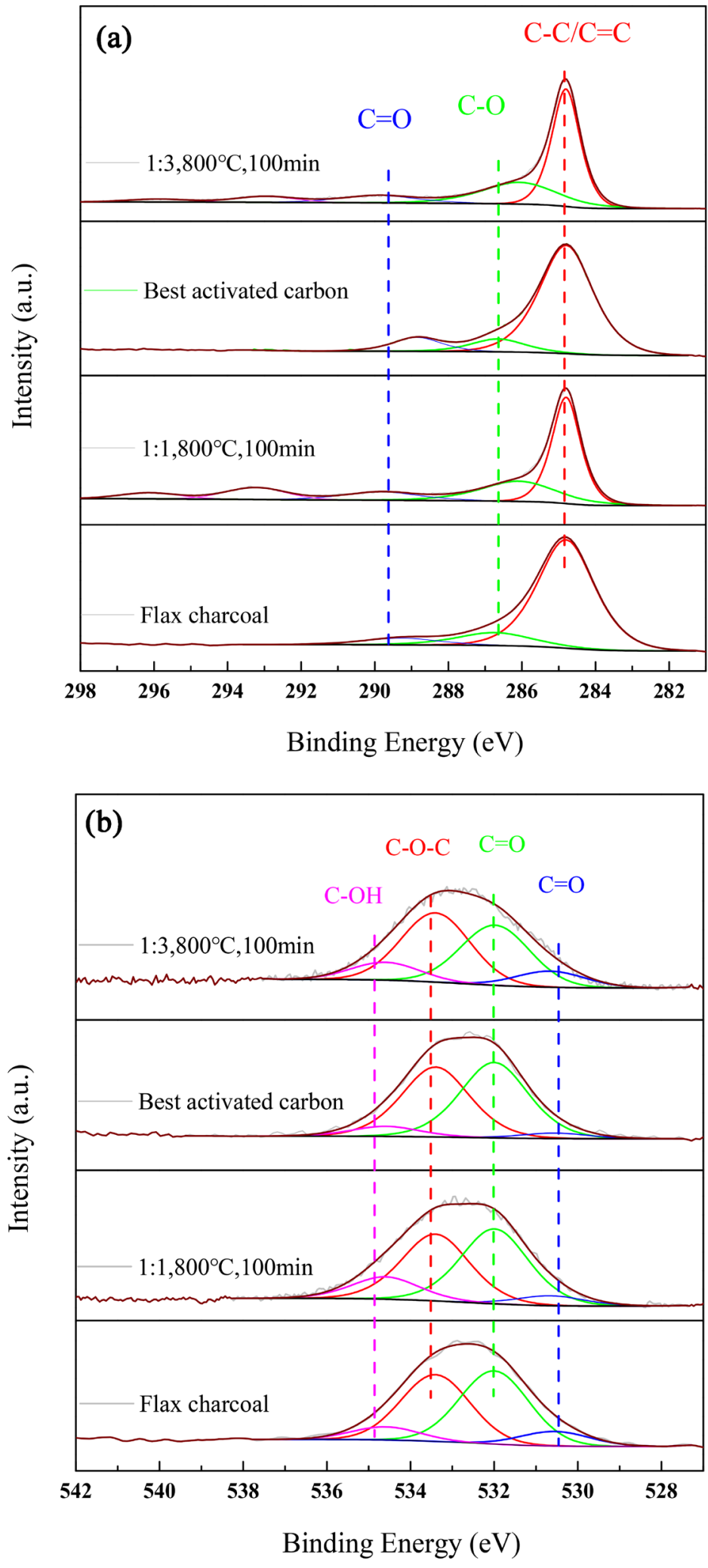


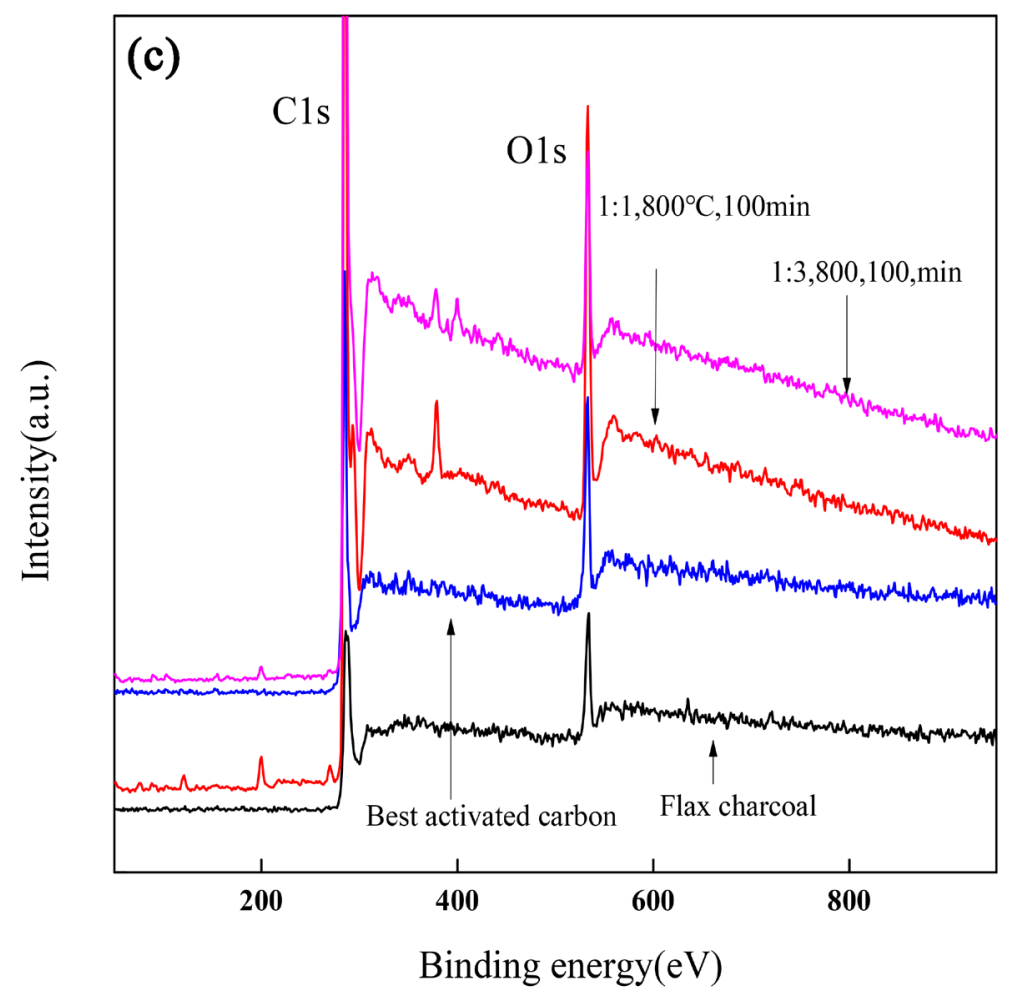

Figure 4. (a) and (b) C1s and O1s spectra; (c) Full spectra of activated carbon and flax residue carbon under different activation conditions.

Figure 5(a) showed CV curves of flax residue carbon and activated carbon prepared under different conditions at scanning rate of $50 \mathrm{mV} / \mathrm{s}$. Compared with other activated carbon, optimized activated carbon had the largest area.

Figure 5(b) showed CV curves of activated carbon prepared under optimized activation conditions at different scanning rates. As observed, CV curves of activated carbon at scanning rate of $200 \mathrm{mV} / \mathrm{s}$ still showed a regular rectangular-like shape, indicating its excellent fast charging/discharging characteristics. There was no obvious redox peak in activated carbon, and its capacitance was mainly electric double layer capacitance. The reason might be that the activation temperature increased and the effective oxygen-containing functional groups on the activated carbon were reduced, resulting in lower capacity. The relatively large specific surface area and large number of micropores increased the electric double layer capacitance, so they were mainly electric double layer capacitance. The specific surface area of optimized activated carbon and the proportion of micropores were relatively small, however, oxygen-containing groups were effective [19]. Figure 5(b) showed the CV curves at the scanning rate scanning rate of $10-200 \mathrm{mv} / \mathrm{s}$. The curves at each scanning rate were very close to rectangular shape, indicating that the sample had excellent electric double layer capacitance characteristics. The shape deviated slightly from the regular rectangle at larger scanning rate, which was caused by the stronger pseudocapacitance effect at larger scanning rate. In general, the sample showed good fast charging/discharging characteristics. 

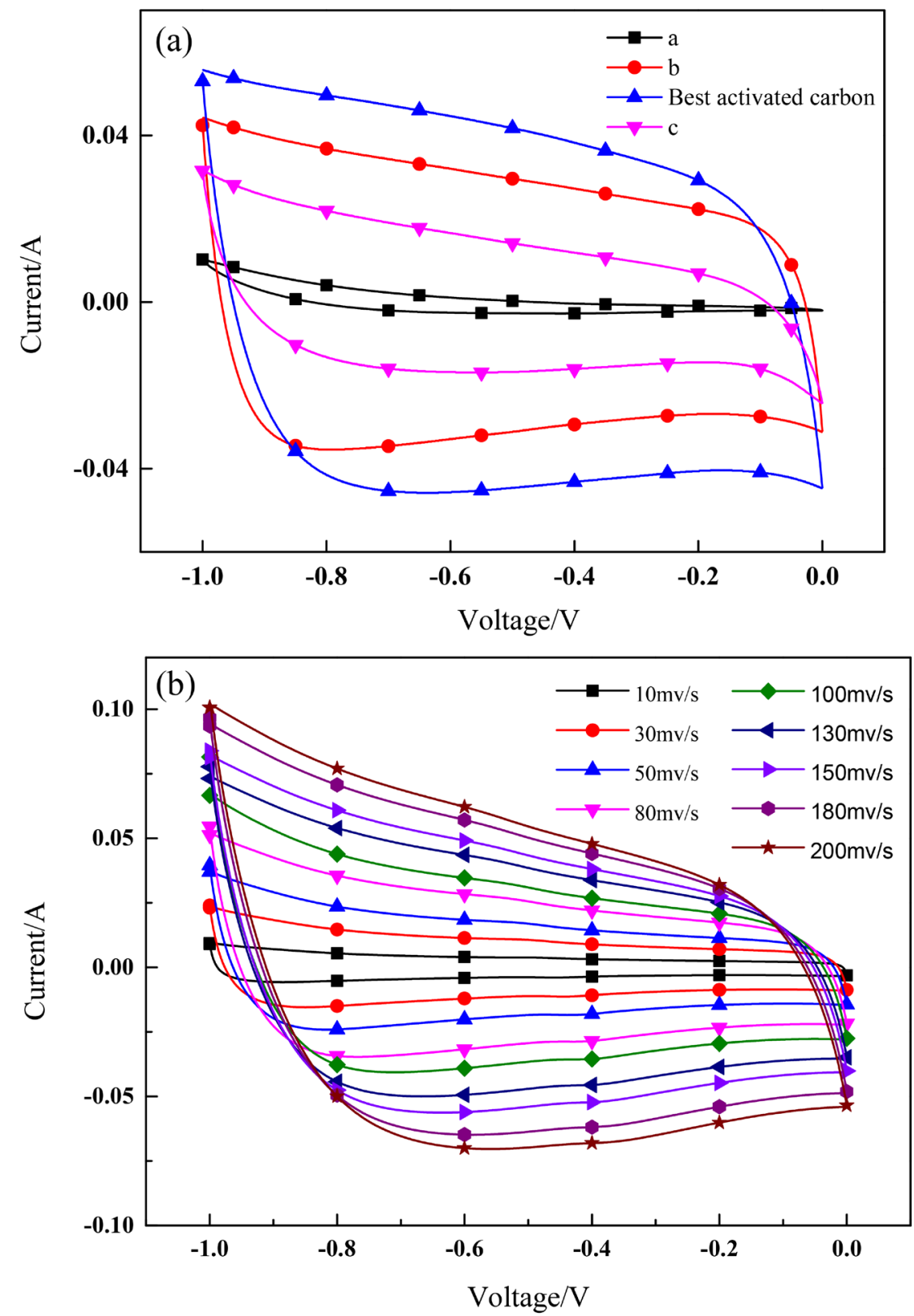

Figure 5. The CV curves of (a) flax residue carbon and activated carbon and (b) activated carbon prepared under optimized activation conditions at different scanning rates.

\subsubsection{Charging/Discharging Performance of Activated Carbon}

Figure 6 showed charging/discharging curves of flax residue carbon and activated carbon prepared under different activation conditions at different current densities. The current density was controlled from 0.1 to $10 \mathrm{~A} / \mathrm{g}$. The analysis was carried out by the shape of the curve and voltage drop. The charging/discharging curves of an ideal capacitor were isosceles with good symmetry, and the charging and discharging curves tended to be straight, and the voltage varied linearly with charging/discharging time.

Figure 6 showed charging/discharging curves of Sample b, Sample c and optimized activated carbon at different current densities. The charging/discharging 


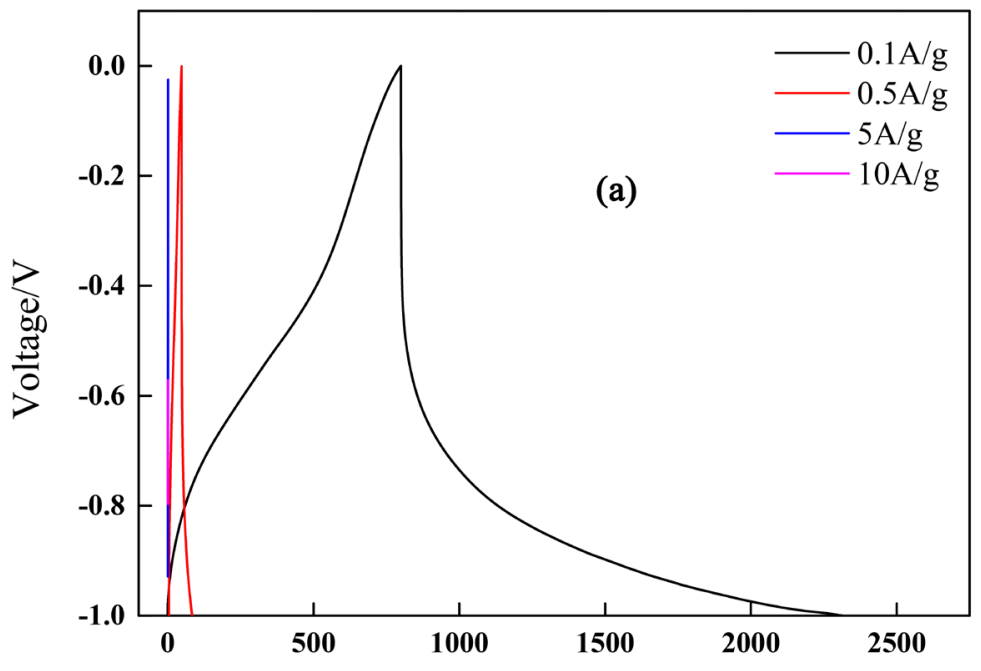

Time/s

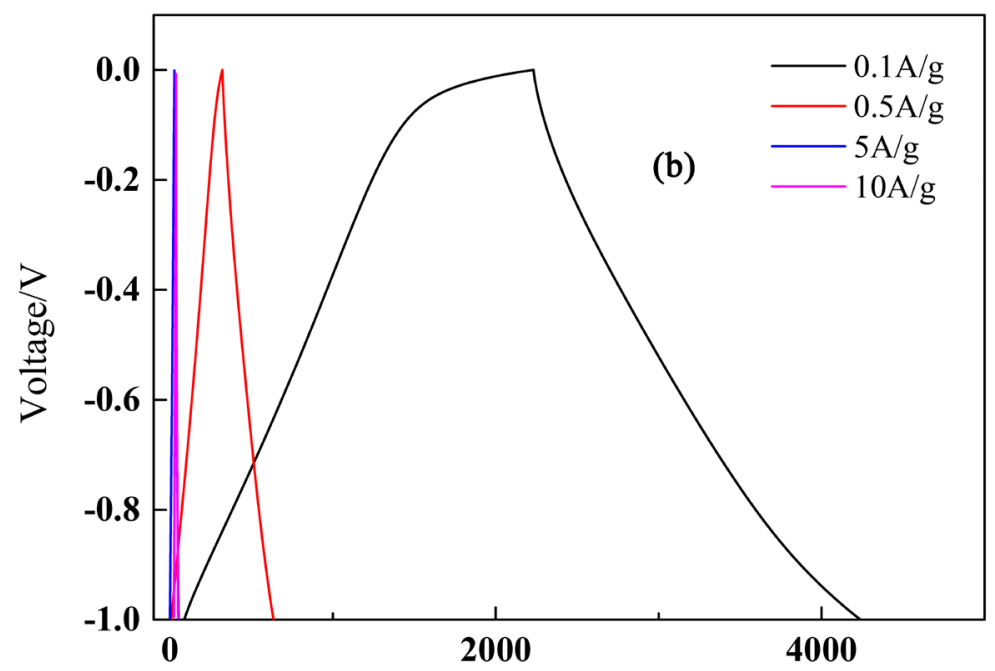

Time/s

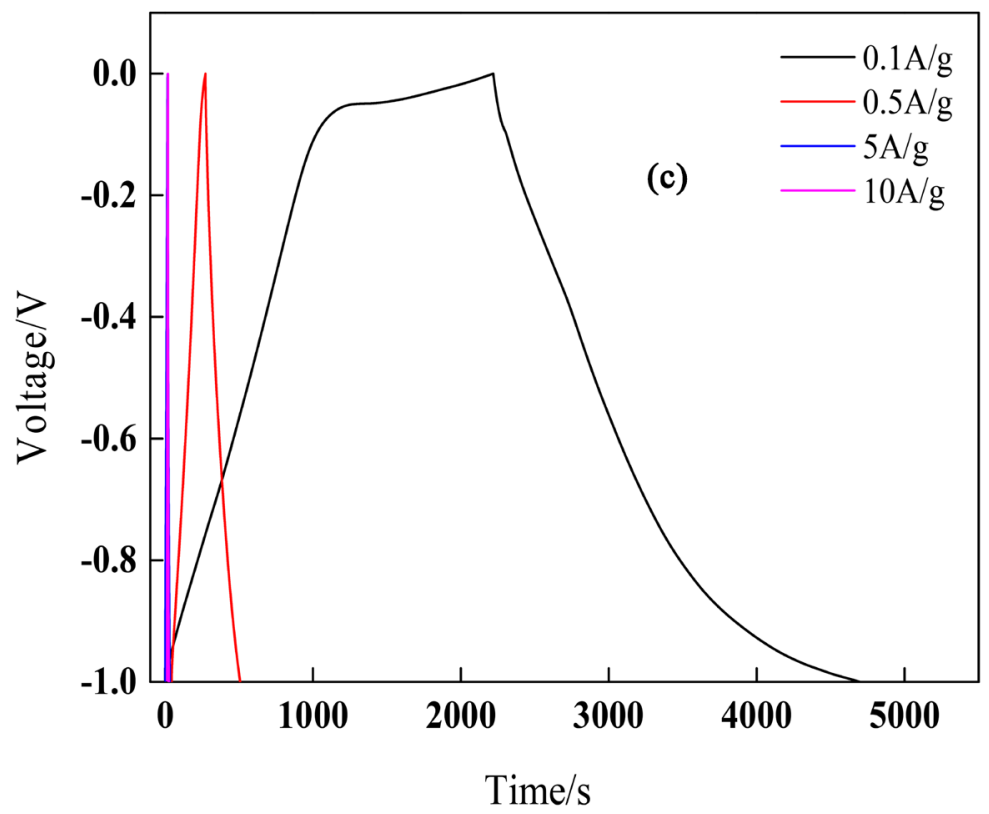




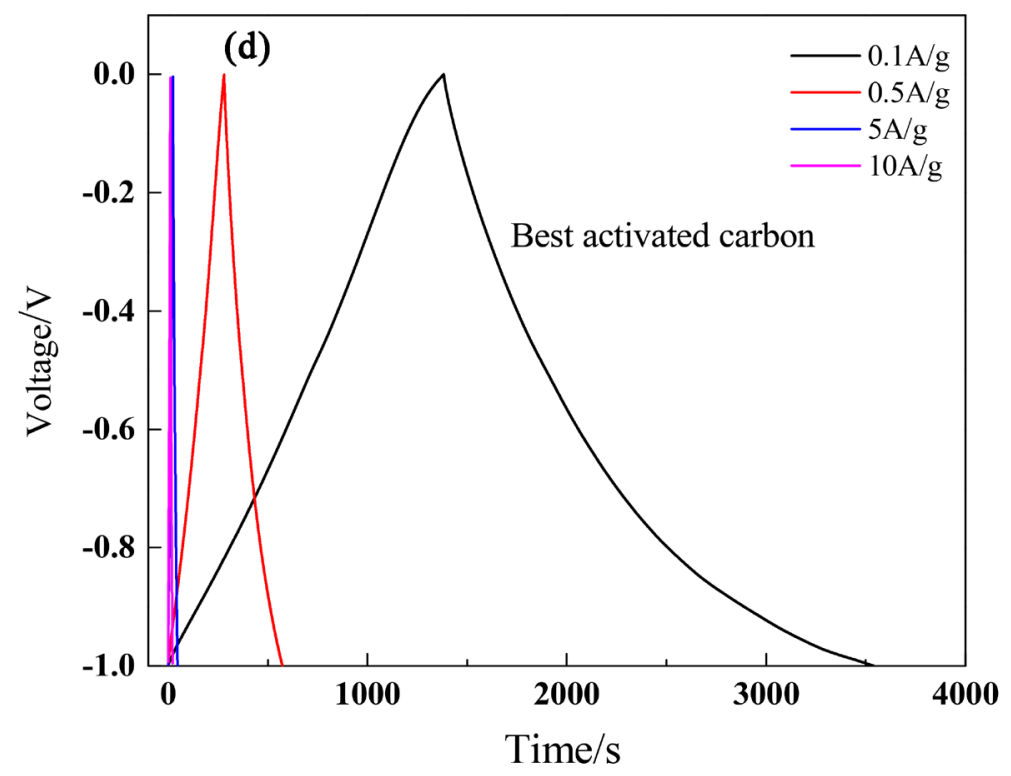

Figure 6. Charge discharge curves of flax residue carbon and activated carbon under different activation conditions.

curve of optimized activated carbon was triangular, indicating that the capacitance of flax residue based porous activated carbon prepared by the $\mathrm{KOH}$ method was composed of electric double layers, and the discharge curve of activated carbon was close to a straight line, indicating that pseudocapacitance of activated carbon was low. The conclusion was consistent with CV curves in Figure 5(a). The specific capacitance of samples without $\mathrm{KOH}$ activation was much smaller than that of activated carbon. The specific capacitances of flax residue carbon at current density of 0.5 and $10 \mathrm{~A} / \mathrm{g}$ were 17.8 and $5 \mathrm{~F} / \mathrm{g}$, respectively. The poor capacitance retention suggested that the original sample had low capacitance performance and poor rate performance when used as electrode material. The specific capacitance of the samples activated by $\mathrm{KOH}$ was significantly improved, indicating that the flax residue based porous activated carbon prepared by the $\mathrm{KOH}$ activation method had excellent electrochemical performance. This was attributed to the fact that activated carbon contained abundant effective oxygen-containing functional groups on surface, and specific surface area was large. The capacitance retention rates of optimized activated carbon, $b$ and $c$ were $53 \%$, $44 \%$ and $40 \%$, respectively, showing good rate characteristics. However, the specific capacitance of both was lower than that of optimized activated carbon, which might be related to the low impregnation ratio, insufficient activation or the high impregnation ratio severely destroying the carbon layer structure.

Due to the internal resistance of the electrodes, when the polarity of the charge changed, there was a sharp drop in voltage during the initial stage of discharge, which was called voltage drop. The voltage drops of flax carbon and activated carbon prepared under different activation conditions were shown in Table 3.

As shown in Table 3, with the increase of current density, the voltage drop 
gradually increased. The voltage drops of charging/discharging curves of activated carbon prepared under optimized was small, and the charging/discharging curves had isosceles distribution under different current densities, indicating good conductivity. According to Figure 6 and Table 3, activated carbon prepared under optimized conditions was regarded as the optimized electrode material and its specific capacitance per mass at current density of $0.1 \mathrm{~A} / \mathrm{g}$ was $215.7 \mathrm{~F} / \mathrm{g}$.

\subsubsection{Characterization by EIS}

Figure 7 showed electrochemical impedances of flax residue carbon and activated carbon prepared under different activation conditions. Figure 7 showed Nyquist curves of optimized activated carbon, Sample a, Sample b and Sample c at frequency of $10 \mathrm{mHz}-100 \mathrm{kHz}$. The impedance curves of activated carbon were almost vertical in the lower frequency region, indicating that the electrode material had small electrolyte ions diffusion resistance and good capacitance performance. The curve of flax residue carbon had the smallest angle with the real axis in the low frequency region, indicating that it had poor capacitive performance. The large ion diffusion resistance inside the electrode material was

Table 3. Voltage drop of flax residue carbon and activated carbon under different current density (V).

\begin{tabular}{cccc}
\hline Sample & $\mathbf{0 . 5 ~ A / g}$ & $\mathbf{1 ~ A} / \mathbf{g}$ & $\mathbf{5 ~ A / g}$ \\
\hline $\mathrm{a}$ & 0.123 & 0.257 & 0.535 \\
$\mathrm{~b}$ & 0.005 & 0.042 & 0.080 \\
Activated carbon prepared under optimized conditions & 0.007 & 0.013 & 0.062 \\
$\mathrm{c}$ & 0.011 & 0.102 & 0.213 \\
\hline
\end{tabular}

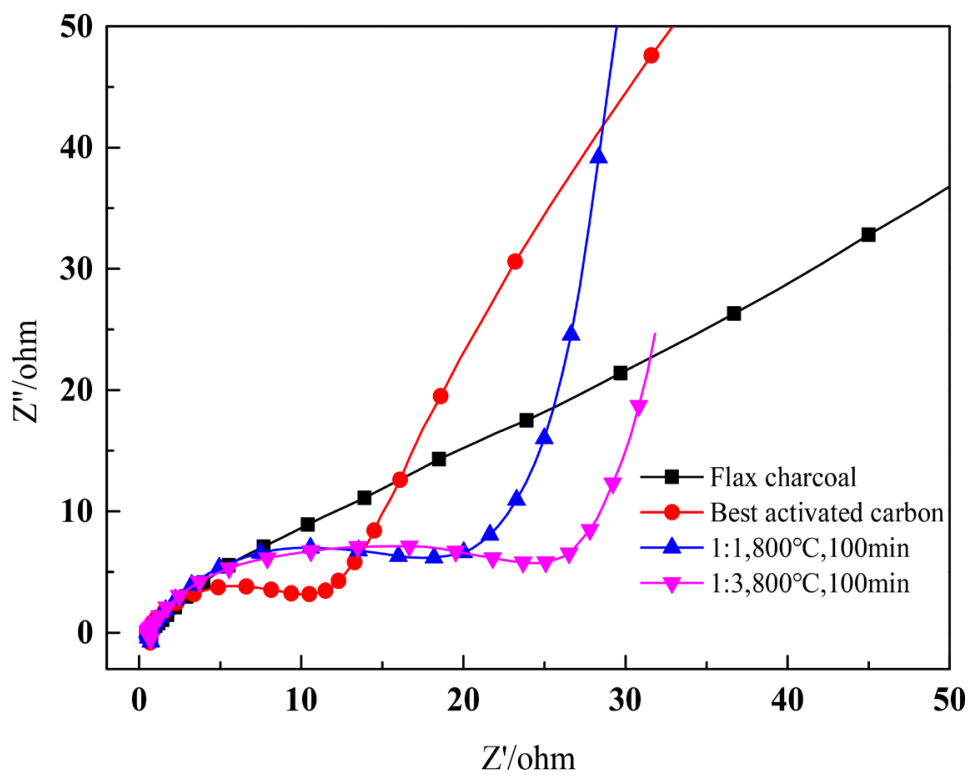

Figure 7. Impedance curves of flax residue carbon and activated carbon under different activation conditions. 
not conducive to the diffusion and transportation of electrolyte. In the high frequency region, the semicircular arc of the optimized activated carbon curve was small, which indicated that the charge transfer resistance of the electrode material was small and had good electrical conductivity; in the low frequency region, the curve was basically perpendicular to the horizontal axis, which indicated that the material had ideal capacitance characteristics, and there were negative values below the real axis in the high frequency region. This indicated that the impedance of the sample was low [25].

Based on the above analysis results, it can be seen that activated carbon prepared under optimized conditions had the maximum specific capacitance, the polarization resistance was small, the charge transfer resistance was low, and the transmission resistance of electrolyte ions was small [26]. Therefore, activated carbon electrodes prepared under this activation condition had better electrochemical performance.

\section{Conclusion}

Activated carbon prepared by the $\mathrm{KOH}$ method was highly disordered non-graphitized carbon. $\mathrm{C}=\mathrm{O}$ groups on activated carbon played an important role in enhancing electrochemical performance. Activated carbon prepared at an impregnation ratio of $1: 2$, activation temperature of $800^{\circ} \mathrm{C}$ and activation time of 100 min was regarded as the optimized electrode material.

\section{Conflicts of Interest}

The authors declare no conflicts of interest regarding the publication of this paper.

\section{References}

[1] Lin, A., Hu, J., Zhang, L. and Zhang, B. (2005) Resource Environment and Sustainable Development. Doctoral Thesis, Wuhan University, Wuhan.

[2] Wang, G. (2011) Preparation and Properties of Electrode Materials for Supercapacitors. Doctoral Thesis, Tsinghua University, Beijing.

[3] Wu, M., Cao, X., An, Z., Yang, E. and Hua, L. (2011) Study on the Ratio of Positive and Negative Capacity of $\mathrm{LiNi}_{1 / 3} \mathrm{CO}_{1 / 3} \mathrm{Mn}_{1 / 3} \mathrm{O}_{2} / \mathrm{Ac}$ Hybrid Super Capacitor. Electronic Components and Materials, 30, 34-37.

[4] Li, Y., Li, J. and Duan, L. (2010) Research Progress of Electrode Materials for High Performance Super Capacitors. Hebei Industrial Technology, 27, 56-59.

[5] Mao, C. (2015) Study on the Preparation Performance of Activated Carbon for Super Capacitor Electrode Materials. Doctoral Thesis, Southeast University, Nanjing.

[6] Ye, J. and Zhu, Y. (2017) Preparation of Porous Carbon Electrode Materials for Supercapacitors by Activation of Potassium Hydroxide. Electrochemistry, 23, 548-559.

[7] Cao, Y., Wang, K., Wang, X., Gu, Z., Fan, Q., Gibbons, W., et al. (2016) Hierarchical Porous Activated Carbon for Supercapacitor Derived from Corn Stalk Core by Potassium Hydroxide Activation. Electrochimica Acta, 212, 839-847. https://doi.org/10.1016/j.electacta.2016.07.069

[8] Li, J., Wei, B., Wang, C., Zhou, Z. and Lv, Z. (2018) High-Performance and Stable 
$\mathrm{La}_{0.8} \mathrm{Sr}_{0.2} \mathrm{Fe}_{0.9} \mathrm{Nb}_{0.1} \mathrm{O}_{3-\delta}$ Anode for Direct Carbon Solid Oxide Fuel Cells Fueled by Activated Carbon and Corn Straw Derived Carbon. International Journal of $\mathrm{Hy}$ drogen Energy, 43, 12358-12367. https://doi.org/10.1016/j.ijhydene.2018.04.176

[9] Wang, Y., Su, W., Liu, Co., Shi, Z. and Zhou, Y. (2008) Application of Coconut Shell Activated Carbon as Electrode Material and Adsorbent. Forest Products Chemistry and Industry, 28, 60-64.

[10] Liu, D., Zhang, W. and Huang, W. (2019) Effect of Removing Silica in Rice Husk for the Preparation of Activated Carbon for Supercapacitor Applications. Chinese Chemical Letters, 30, 1315-1319. https://doi.org/10.1016/j.cclet.2019.02.031

[11] Li, H., Li, H. and Yin, Y. (2019) Optimization Preparation and Characterization of Pepper Straw Based Activated Carbon Electrode Materials. Journal of Shaanxi University of Science and Technology, 37, 107-113.

[12] Yang, S., Liu, Z., Hou, J. and Zhou, Y. (2016) Preparation and Performance of Mixed Catalyst of $\mathrm{MnO}_{2}$ and Activated Carbon for Microbial Fuel Cell. Renewable Energy, 34, 311-316.

[13] Song, L., Zhang, D., Bai, R., Wen, H. and Feng, K. (2015) Study on Performance of Nickel Based Biocathode Microbial Fuel Cell Catalyzed by Activated Carbon and $\mathrm{TiO}_{2}$. Renewable Energy, 33, 612-617.

[14] Zhou, F. (2015) Preparation and Capacitance Properties of Biomass Based Nanoporous Carbon Composites. Doctoral Thesis, Shanghai Jiaotong University, Shanghai.

[15] Wang, J.C. and Kaskel, S. (2012) KOH Activation of Carbon-Based Materials for Energy Storage. Journal of Materials Chemistry, 22, 23710-23725. https://doi.org/10.1039/C2JM34066F

[16] Pokrzywinski, J., Keum, J.K., Ruther, R.E., Self, E.C., Chi, M., Mitlin, D., et al. (2017) Unrivaled Combination of Surface Area and Pore Volume in Micelle-Templated Carbon for Supercapacitor Energy Storage. Journal of Materials Chemistry A, 5, 1351113525. https://doi.org/10.1039/C7TA03655H

[17] Liu, L., Lu, J., Zhang, Y.X., Liu, M., Yu, Y.F. and Chen, A.B. (2017) Synthesis of Nitrogen-Doped Graphitic Carbon Nano-Capsules from a Poly (Ionic Liquid) for $\mathrm{CO}_{2}$ Capture. New Carbon Materials, 32, 380-384. https://doi.org/10.1016/S1872-5805(17)60129-X

[18] Liu, Z., Yang, Y., Du, Z., Xing, W., Komarneni, S., Zhang, Z., et al. (2015) Furfuralcohol Co-Polymerized Urea Formaldehyde Resin-Derived N-Doped Microporous Carbon for $\mathrm{CO}_{2}$ Capture. Nanoscale Research Letters, 10, Article No. 333. https://doi.org/10.1186/s11671-015-1041-x

[19] Wang, Y. (2019) Study on the Preparation and Properties of Hemp Based Porous Carbon by Strong Oxidant Activation Method. Doctoral Thesis, Beijing University of Chemical Technology, Beijing.

[20] Xu, B., Zheng, D., Jia, M., Cao, J. and Yang, Y. (2013) Nitrogen-Doped Porous carbon Simply Prepared by Pyrolyzing a Nitrogen-Containing Organic Salt for Supercapacitors. Electrochimica Acta, 98, 176-182.

https://doi.org/10.1016/j.electacta.2013.03.053

[21] Biniak, S., Szymański, G., Siedlewski, J. and Wiątkowski, A. (1997) The Characterization of Activated Carbons with Oxygen and Nitrogen Surface Groups. Carbon, 35, 1799-1810. https://doi.org/10.1016/S0008-6223(97)00096-1

[22] Fang, Y., Luo, B., Jia, Y., Li, X., Wang, B., Song, Q., et al. (2012) Renewing Functionalized Graphene as Electrodes for High-Performance Supercapacitors. Advanced Materials, 24, 6348-6355. https://doi.org/10.1002/adma.201202774 
[23] Young, S.Y., Park, M.H., Hong, S.J., Lee, M.E., Park, Y.W. and Jin, H.-J. (2015) Hierarchically Porous Carbon Nanosheets from Waste Coffee Grounds for Supercapacitors. ACS Applied Materials \& Interfaces, 7, 3684-3690. https://doi.org/10.1021/am5081919

[24] Zhao, Z., Wang, Y., Li, M. and Yu, R. (2015) High-Performance N-Doped Porous Activated Carbon Based on Chicken Feather for Supercapacitors and $\mathrm{CO}_{2}$ Capture. RSC Advances, 5, 34803-34811. https://doi.org/10.1039/C5RA01569C

[25] Jia, Z., Dai, C. and Chen, L. (2006) Electrochemical Measurement Method. Chemical Industry Press, Shanghai.

[26] Wu, C. (2016) Preparation and Energy Storage Behavior of Soybean Meal Activated Carbon Electrode Materials for Supercapacitors. Doctoral Thesis, Yanshan University, Hebei. 